\title{
STRATEGI KOMUNIKASI KOMUNITAS VIRTUAL DALAM MEMPROMOSIKAN TANGERANG MELALUI MEDIA SOSIAL
}

\author{
Tanty Dewi Permassanty ${ }^{1}$, Muntiani ${ }^{2}$ \\ ${ }^{1,2}$ Fakultas Sosial dan Ekonomi, Program Studi Ilmu Komunikasi, Universitas Surya \\ Grand Serpong Mall Lt. 1 Unit F8 \& F9, Jl. M.H. Thamrin Km 2,7, Kota Tangerang, Banten, Indonesia \\ No. Telp./HP: ${ }^{1} 0817150084,{ }^{2} 085817181699$ \\ E-mail:1'tanty.dewi@surya.ac.id, ${ }^{2}$ muntiani9@gmail.com
}

Naskah diterima tanggal 4 April 2018, direvisi tanggal 9 Oktober 2018, disetujui tanggal 6 November 2018

\section{VIRTUAL COMMUNITY COMMUNICATION STRATEGY IN PROMOTING TANGERANG THROUGH SOCIAL MEDIA}

\begin{abstract}
The growth of Information and Communication Technology has made the number of Internet users to increase, including in Indonesia. Besides Facebook and Twitter, the very popular and fast-growing social media was Instagram. Instagram has become an alternative choice of several groups in promoting activities, one of them is AboutTNG community that is a virtual community that use Instagram in promoting Tangerang City. The purpose of this study was to discover and to understand the communication strategy AboutTNG community in promoting Tangerang through Instagram. This research use the concept of virtual community, promotion, and communication strategy theory of Machmud Machfoedz by analyzing message and media strategy. In this case, the researchers use constructive paradigms and case study methods to achieve in-depth result. The result of this research show that the message and media strategy used by AboutTNG in promoting Tangerang has been successful. This can be observed by the significant increase of Instagram accounts@abouttng followers and the effect of the message delivered has change their actions, such as participate in events held and visit places that publishedby@abouttng, such as nature and historical tours, culinary, and city icons in Tangerang. The@abouttng account develops various message strategies, from photo editing, applying message content, structure, and message format to each content uploaded, and the message packaging using Instagram features.
\end{abstract}

Keywords: communication strategy, social networking, instagram, promotion, AboutTNG virtual community.

Abstrak. Perkembangan Teknologi Informasi dan Komunikasi membuat jumlah pengguna internet semakin meningkat, termasuk di Indonesia. Selain Facebook dan Twitter, media yang sangat populer dan tumbuh dengan cepat adalah Instagram. Jejaring sosial Instagram menjadi pilihan beberapa kelompok dalam melakukan aktivitas promosi, salah satunya komunitas AboutTNG yaitu komunitas virtual yang memanfaatkan Instagram dalam mempromosikan Kota Tangerang. Penelitian ini bertujuan mengetahui dan memahami strategi komunikasi komunitas AboutTNG dalam mempromosikan Tangerang melalui Instagram. Penelitian ini menggunakan konsep komunitas virtual, promosi, dan teori strategi komunikasi Machmud Machfoedz dengan menganalisis strategi pesan dan strategi media. Dalam hal ini, peneliti menggunakan paradigma konstruktivis dan metode studi kasus untuk memperoleh hasil secara mendalam. Hasil penelitian menunjukkan bahwa strategi pesan dan strategi media yang digunakan AboutTNG dalam mempromosikan Tangerang telah berhasil. Hal ini terlihat dari kenaikan jumlah followers akun Instagram@abouttng yang signifikan dan efek pesan yang disampaikan telah mengubah tindakan followers, yaitu followers mau mengikuti event-event yang diselenggarakan@abouttng hingga mau mengunjungi tempat yang dipublikasikan, seperti wisata alam, wisata sejarah, kuliner, dan ikon kota di Tangerang. Akun@abouttng mengembangkan beragam strategi pesan, mulai dari 
melakukan editing pada foto, menerapkan isi pesan, struktur, dan format pesan pada setiap konten yang diunggah, penulisan caption dengan berbagai cara kreatif, dan pengemasan pesan memanfaatkan fitur-fitur Instagram.

Kata kunci: strategi komunikasi, jejaring sosial, instagram, promosi, komunitas virtual AboutTNG.

\section{PENDAHULUAN}

Perkembangan Teknologi Informasi dan Komunikasi bergerak sangat cepat dan telah membawa perubahan pada tatanan kehidupan sosial manusia termasuk juga dalam pola komunikasi, sehingga manusia tidak lagi mempermasalahkan jarak, batas, ruang, dan waktu dalam berkomunikasi. Kemajuan Teknologi Informasi dan Komunikasi juga telah menghadirkan "dunia dalam genggaman". Istilah ini seperti ungkapan Thomas L. Friedman yang dikutip Nasrullah (2015), the world is flat yaitu keadaan dunia yang semakin rata karena setiap orang dapat mengakses informasi apa pun melalui internet.

Internet menjadi pendorong pesatnya perkembangan Teknologi Informasi dan Komunikasi yang menghadirkan wujud baru dalam bentuk media yang disebut new media (media baru). Karakteristik utama media baru adalah jaringan (network). Menurut Nasrullah, karakteristik ini membuat pengguna lebih mudah menjalin hubungan dengan pengguna lain dan memperluas partisipasi di media. Selain itu, karakter yang membedakan media lama dengan media baru adalah interactivity. Jika istilah broadcast mewakili kondisi media lama, maka interactivity mewakili media baru (Nasrullah, 2014). Graham dalam Nasrullah (2014) menjelaskan bahwa karakteristik interactivity memungkinkan pengguna dan perangkat saling terhubung secara interaktif.

Salah satu medium di media siber yang memiliki karakteristik berbeda dengan medium lainnya yaitu media sosial. Beranjak dari pemahaman bahwa media ini digunakan sebagai sarana untuk berhubungan sosial di dunia virtual menjadi ciri khusus media sosial (Nasrullah, 2015). Mayfield dalam Apriliani, Putri \& Ali (2015) mengungkapkan beberapa karakteristik media sosial, antara lain ada keterlibatan antara penggunanya (participants), komunikasi dua arah (openness), terbentuknya komunitas (community), dan jaringan (connectedness).

Nasrullah (2015) membagi media sosial menjadi enam kategori yaitu: (1) Jejaring sosial (social networking) seperti: Facebook, LinkedIn, dan Instagram. (2) Jurnal online (blog) yaitu jenis media sosial seperti personal homepages dengan domain .com atau .id dan weblog gratis seperti Wordpress dan Blogger. (3) Jurnal online sederhana atau microblogging seperti Twitter. (4) Media berbagi seperti Youtube. (5) Penanda sosial (social bookmarking) yaitu media sosial yang mengorganisir, menyimpan, dan mencari informasi secara online, contohnya: situs Digg.com dan Reddit.com, dan terakhir (6) Media konten bersama, seperti Wikipedia. Dari data survei APJII menunjukkan bahwa media sosial yang populer di Indonesia, pertama adalah jejaring sosial Facebook lalu diikuti Instagram, YouTube, Google+ dan Twitter (APJII, 2016). Meskipun tergolong baru muncul dibandingkan Facebook dan Twitter, Instagram menjadi salah satu jejaring sosial yang sangat populer dan jejaring sosial yang tumbuh dengan sangat cepat.

Sesuai dengan perkembangannya, kini jejaring sosial tidak hanya digunakan untuk menampilkan sosok penggunanya agar dikenal orang lain tetapi juga menjadi media promosi. Banyak organisasi atau kelompok memanfaatkannya untuk menjalankan fungsi komunikasi (menjalin hubungan dengan target audiens) dan fungsi penjualan. Hal ini ditegaskan dalam situs Tempo.co (Hestya, 2013) bahwa jejaring sosial telah beralih fungsi sebagai media promosi. Aktivitas promosi yang dilakukan melalui jejaring sosial ini disebut dengan internet marketing, yaitu aktivitas pemasaran apapun yang dilakukan secara online menggunakan teknologi internet (Jones, Malczyk \& Beneke, 2011). 
Potensi jejaring sosial yang sifatnya low cost high impact menjadi media efektif untuk mempromosikan sebuah produk atau informasi dengan menjangkau khalayak luas (Maryati, 2016). Dilansir dari Tempo.co (Hestya, 2013), jejaring sosial yang menjadi media promosi paling sukses adalah Instagram. Konten Instagram yang lebih visual membuat banyak instansi memanfaatkannya sebagai media dalam mempromosikan produk, menyebarluaskan informasi baik politik, kuliner, wisata, budaya, dan kegiatan. Selain pengguna seperti perusahaan, musisi, dan komunitas juga dapat menggunakannya untuk memperkenalkan karyanya kepada pasar yang luas dengan lebih mudah dan biaya rendah (Ahmad, Nursih \& Praceka, 2014).

Salah satu kelompok yang memanfaatkan jejaring sosial sebagai media untuk mempromosikan sebuah kota adalah Komunitas Virtual AboutTNG. Komunitas yang berlokasi di Tangerang ini merupakan komunitas movement changes yang ingin memperkenalkan wilayah Tangerang (Tangerang, Kab. Tangerang, dan Tangerang Selatan) melalui media sosial untuk menumbuhkan rasa peduli, cinta, dan bangga anak muda kepada tempat tinggalnya sebagai upaya menciptakan perubahan positif (AboutTNG, 2015).

Penggagas Komunitas AboutTNG yaitu Erwin Setiawan mengungkapkan bahwa komunitas ini didirikan karena pada kenyataannya banyak anak muda Tangerang yang tidak mengenal hal-hal yang berkaitan dengan kotanya sendiri seperti: wisata-wisata budaya kuno, tempat wisata terbaru, berita terupdate, dan lain-lain. Selain itu, dengan adanya komunitas ini diharapkan dapat membantu Pemerintah Kota Tangerang untuk mempromosikan Kota Tangerang kepada masyarakat luas melalui media sosial, meskipun selama ini Erwin memaparkan bahwa tidak ada kontribusi dari Pemerintah Kota Tangerang karena semua ide dan program muncul dari insiatif sekelompok anak muda yang mengelola komunitas tersebut (Hasil Wawancara, 12 Mei 2017).

Kurangnya peran Pemerintah Kota Tangerang dalam memperkenalkan Kota Tangerang kepada masyarakat luas juga menjadi dasar utama didirikannya Komunitas AboutTNG.

Sejak media sosial Komunitas AboutTNG diaktifkan pada Bulan November 2014, hingga 25 Mei 2017 fanpage Facebook @abouttng sudah disukai oleh 1.917 pengguna, 7.829 pengikut di akun Twitter, 101.661 pengikut di Instagram, dan di Line diikuti oleh 44.335 akun. Sementara itu, jumlah subscriber di channel Youtube hanya 23 dan pengikut di Google+ hanya 52. Dari data pengikut media sosial tersebut menunjukkan bahwa akun Instagram @abouttng memiliki jumlah pengikut yang paling banyak. Selain itu, founder AboutTNG juga mengungkapkan bahwa pemanfaatan jejaring sosial Instagram dalam mempromosikan Tangerang membawa dampak yang signifikan, sepeti banyaknya followers akun@abouttng yang berkunjung ke tempat-tempat wisata di Tangerang. Hal ini terbukti dari terkenalnya beberapa destinasi wisata, seperti Hutan Mangrove, Teluk Naga, sejak sering dipublikasikan oleh akun Instagram@abouttng. Terkenalnya destinasi wisata tersebut diketahui dari banyaknya pengguna Instagram yang me-mention akun (a)abouttng saat mengunggah foto mereka ke Instagram (Hasil Wawancara, 12 Mei 2017).

Keberhasilan AboutTNG dalam mempromosikan Tangerang melalui Instagram tersebut yang mendasari peneliti tertarik untuk mengeksplorasi lebih dalam mengenai strategi komunikasi komunitas AboutTNG dalam mempromosikan Tangerang melalui jejaring sosial Instagram.

Dalam membantu Pemerintah Tangerang untuk mempromosikan sebuah kota, AboutTNG tentunya harus menyusun strategi pesan dan strategi media yang sesuai dengan target audiensnya agar tujuan yang diinginkan dapat tercapai. Hal ini didasarkan pada teori strategi komunikasi Machfoedz (2010) bahwa dua strategi utama yang harus dilakukan pemasar untuk mencapai tujuan komunikasi adalah strategi pesan dan strategi media.

Tujuan penelitian ini adalah untuk mengetahui penyusunan strategi komunikasi AboutTNG dalam mempromosikan Tangerang adalah menumbuhkan rasa peduli, bangga, dan cinta anak muda terhadap 
Tangerang. Jika strategi komunikasi dilakukan dengan perencanaan yang baik, dan konsisten, pengelola jejaring sosial AboutTNG mampu menyusun strategi pesan yang efektif dalam memersuasi khalayak, dan didukung dengan materi unggahan kreatif, maka akan membawa dampak signifikan pada pencapaian tujuan yang telah ditentukan (Maryati, 2016).

\section{Tujuan Penelitian}

Berdasarkan rumusan masalah tersebut, tujuan umum penelitian yang ingin dicapai dalam penelitian ini yaitu untuk mendeskripsikan strategi komunikasi yang digunakan AboutTNG dalam mempromosikan Tangerang melalui jejaring sosial Instagram. Adapun tujuan khusus penelitiannya adalah:

1. Untuk mendeskripsikan strategi pesan yang digunakan Komunitas Virtual AboutTNG dalam mempromosikan Tangerang melalui jejaring sosial Instagram.

2. Untuk mendeskripsikan strategi media yang digunakan Komunitas Virtual AboutTNG dalam mempromosikan Tangerang melalui jejaring sosial Instagram.

\section{LANDASAN KONSEP}

\section{Media Baru}

Everest memaparkan bahwa karakter new media adalah individualisasi dan interaktivitas (Septiawan, 2015). Individualisasi yaitu pengguna internet memiliki peluang dalam mengontrol arus informasi, sedangkan interaktivitas yaitu kemampuan yang membuat pengguna dapat berinteraksi langsung dengan pengguna lain. Sementara itu, Gane dan Beer (dalam Nasrullah, 2014) memaparkan beberapa karakteristik media baru, yaitu:

- Network, disebut jaringan untuk massa yang memungkinkan pengguna dapat dengan mudah memperluas partisipasi dalam media.

- Interactivity, jika istilah broadcast mewakili kondisi media lama, maka interactivity mewakili media baru.
- Information, yaitu tersajinya informasi yang membanjiri dunia virtual di internet.

- Interface, merupakan karakteristik yang menghubungkan interaksi antara pengguna, komputer dan jaringan sehingga menghilangkan hambatan jarak dan waktu dalam berkomunikasi.

- Archive, yaitu karakteristik yang memungkinkan pengguna dapat mengubah, mengakses, menghasilkan, dan menyimpan informasi dari internet.

- Simulated, yaitu realitas dalam internet yang memungkinkan seseorang memanipulasi identitas dan representasi dirinya.

\section{Media Sosial}

Berbicara mengenai media baru tentu saja tidak akan lepas dengan media sosial yang telah menjadi bagian dari kehidupan masyarakat modern. Boyd yang dikutip Nasrullah (2015) mendefinisikan media sosial sebagai kumpulan perangkat lunak yang memungkinkan individu maupun komunitas untuk berkumpul, berbagi, berkomunikasi, dan dalam kasus tertentu saling berkolaborasi atau bermain. Media sosial memiliki kekuatan pada User Generated Content (UGC) yaitu konten dihasilkan oleh pengguna, bukan oleh editor sebagaimana di institusi media massa.

Menurut Mieke dan Young dalam Nasrullah (2015), media sosial adalah gabungan antara komunikasi personal dalam arti saling berbagi antar individu (to be shared one-to-one) dan juga media publik yang menyampaikan pesan untuk siapa saja tanpa ada kekhususan sebagai individu (Nasrullah, 2015).

Tidak terbatas oleh jarak dan waktu, serta kontennya dapat diakses di mana pun dan kapan pun menyebabkan kehadiran internet dan media-media di dalamnya seperti media sosial menjadi lebih mendominasi. Hal ini ditegaskan dalam penelitian yang dipublikasikan oleh Crowdtap, Ipsos MediaCT, dan The Wall Street Journal pada Tahun 2014 bahwa jumlah waktu yang dihabiskan khalayak dalam mengakses internet dan media sosial lebih banyak dibandingkan media tradisional (Nasrullah, 2015). 


\section{Instagram}

Instagram merupakan jejaring sosial berbagi foto dan video yang didirikan pada Tahun 2010 oleh perusahaan Burbn, Inc. Jejaring sosial ini memungkinkan setiap penggunanya mengambil foto, melakukan editing, filterisasi pada foto, lalu membagikannya ke layanan jejaring sosial lainnya seperti Facebook, Twitter, dan Tumblr (Utami, Lestari \& Putri, 2016). Nama Instagram diambil dari kata "insta" yang berasal dari kata instan, yang berarti pengguna dapat mengunggah foto secara langsung, dan kata "gram" berasal dari kata telegram yang berfungsi mengirim informasi secara cepat kepada orang lain (Utami, Lestari \& Putri, 2016).

Fitur-fitur menarik menjadi keunggulan Instagram dalam mendorong pertumbuhan penggunanya. Berikut fitur-fitur pada Instagram yang menarik minat penggunanya untuk mengunduh dan menggunakan aplikasi ini, yaitu: follower \& following, kamera, judul foto atau caption foto, editor dan filter foto, hahstag (\#), komentar, tanda suka, popular, slideshow foto (carousel), Instagram stories, dan live video.

\section{Komunitas Virtual}

Rheingold yang dikutip oleh Nasrullah (2015) memaparkan bahwa Internet telah menjadi media para individu untuk berinteraksi hingga pada pelibatan emosi secara virtual. Pelibatan emosi secara virtual inilah yang menjadi salah satu penyebab terbentuknya komunitas virtual. Munculnya media baru (internet) hingga maraknya media sosial saat ini tidak hanya memberi kesempatan untuk berinteraksi lebih dekat dengan relasi atau teman tetapi juga menjadi medium untuk membentuk sebuah komunitas online (Septiawan, 2015). Boyd yang dikutip oleh Akbar (2016) menegaskan bahwa kemunculan media sosial membuat setiap individu dan komunitas dapat berkomunikasi, berbagi, berkumpul, serta saling berkolaborasi. Anggapan pengguna bahwa mereka tidak sendiri di ruang siber membuat mereka bisa membangun hubungan dengan pengguna lainnya. Hal ini yang mendasari terbentuknya komunitas di dunia virtual.
Rheingold (1993) mendefinisikan komunitas virtual sebagai sebuah agregasi sosial yang terbentuk dalam The Net (jaringan yang menghubungkan manusia di seluruh dunia untuk berdiskusi) di saat sejumlah orang melakukan diskusi yang cukup lama tanpa mengesampingkan perasaan (human feeling) dalam membentuk hubungan di siber media. Sementara itu, Nasrullah (2015) mendefinisikan komunitas virtual sebagai komunitas yang terbentuk di dunia siber oleh para pengguna karena adanya kesamaan atau saling melakukan interaksi dan relasi yang difasilitasi oleh medium komputer terkoneksi internet.

Nasrullah (2015) menjelaskan bahwa terbentuknya suatu jaringan atau langsung telah menghubungkan individu dari berbagai tempat untuk saling berinteraksi. Dalam memahami lebih dalam tentang komunitas virtual, Whittaker dalam Gupta \& Kim (2004) mengidentifikasikan beberapa karakteristik utama yang ada pada komunitas virtual, yaitu:

- Ada tujuan, minat, kebutuhan, dan aktivitas bersama yang menjadi alasan utama bergabung dengan sebuah komunitas.

- Partisipasi yang aktif, berulang dan sering, ada interaksi yang cukup sering, ikatan emosional yang kuat, dan berbagi aktivitas bersama.

- Mengakses sumber daya yang sama dan ada kebijakan yang menentukan akses terhadap sumber daya tersebut.

- Saling memberi informasi, dukungan, dan layanan antar anggota komunitas.

- Berbagi dalam konteks kebiasaan, adat istiadat, bahasa, maupun protokol.

\section{Penggunaan Media Sosial dalam Pemasaran (Social Media Marketing)}

Perkembangan teknologi informasi dan komunikasi telah memunculkan istilah baru dalam dunia pemasaran yaitu e-commerce dan internet marketing. E-commerce adalah proses transaksi jual beli yang dilakukan dengan memanfaatkan media internet, sedangkan segala aktivitas penyampaian pesan menggunakan jaringan internet dalam dunia pemasaran disebut dengan pemasaran internet (internet marketing). Jones, Malczyk \& Beneke (2011) mendefinisikan internet 
marketing sebagai aktivitas pemasaran apapun yang dilakukan secara online menggunakan teknologi internet.

Tantangan sekaligus peluang dalam melakukan aktivitas komunikasi pemasaran melalui internet menjadi sebuah gebrakan baru dalam memasarkan produk atau jasa. Internet marketing telah menjadi cabang pemasaran yang cepat berkembang dan paling menarik saat ini (Jones, Malczyk \& Beneke, 2011). Morissan (2010) membahas beberapa kelebihan aktivitas komunikasi pemasaran di internet (internet marketing) dibandingkan dengan media konvensional, antara lain:

- Dapat membidik konsumen yang lebih khusus dan spesifik dibandingkan media konvensional.

- Memiliki pesan khusus dan target konsumen yang terarah sehingga komunikator dapat merancang pesan khusus untuk menarik dan memenuhi kebutuhan target audiensnya.

- Internet memiliki kemampuan interaktif sehingga pengguna internet dapat lebih terlibat dengan produk yang ditawarkan.

- Memiliki kemampuan kreatif sehingga konten di web dan jejaring sosial dapat dirancang dengan lebih menarik sehingga meningkatkan persepsi khalayak.

- Ekspos luas yaitu dengan dana anggaran promosi yang terbatas dapat mempromosikan produk atau jasa lebih potensial dengan jangkauan khalayak luas yang tidak akan didapat di media konvensional.

Selain kelebihan di atas, Morissan (2010) mengungkapkan bahwa sifat interaktif di internet memiliki nilai tambah karena akan ada feedback langsung sehingga pengguna dapat terlibat langsung (real time) tidak seperti pada media konvensional. Menurut Jones, Malczyk \& Beneke (2011) internet marketing memiliki tiga prinsip dasar, yaitu: immediacy, personalisation, dan relevance.

\section{Komponen Strategi Komunikasi Efektif dalam Pemasaran Mahmud Machfoedz}

Dalam sebuah aktivitas pemasaran, pemasar harus mengetahui cara kerja sebuah proses komunikasi (Machfoedz, 2010). Dari elemen-elemen yang ada dalam komunikasi, tahapan dalam mengembangkan komunikasi yang efektif dimulai dari penetapan target audiens, penetapan respon yang diinginkan, memilih pesan, memilih media untuk mengirim pesan, memilih sumber pesan, dan menghimpun umpan balik (Machfoedz, 2010). Dalam memilih sumber pesan, Machfoedz (2010) memaparkan bahwa pemilihan sumber harus tepat agar dapat memersuasi khalayak. Menurut Machfoedz (2010) tiga faktor yang harus diperhatikan dalam memilih sumber pesan agar kredibel adalah: berasal dari ahli, dapat dipercaya, dan disukai. Faktor kepercayaan berkaitan dengan kejujuran dan objektivitas sumber pesan, sedangkan keahlian adalah faktor yang berisi pengakuan atas sesuatu dari seorang ahli, seperti dokter, ilmuwan, dan profesor.

Machfoedz (2010) menjelaskan bahwa tahapan dalam pengembangan strategi komunikasi yang efektif harus dimulai dengan komunikator melakukan identifikasi audiens sasaran, menetapkan respon atau tujuan yang diinginkan, strategi pesan, strategi pemilihan media, hingga menghimpun umpan balik dari audiens. Namun Machfoedz (2010) menegaskan bahwa dua strategi utama yang harus dilakukan pemasar dalam mencapai tujuan komunikasi dalam pemasaran adalah strategi pesan dan strategi media. Komunikator harus menyampaikan pesan dengan benar dengan mempertimbangkan cara audiens mengelolanya dan pesan harus disampaikan melalui media yang sesuai dengan target audiens (Machfoedz, 2010).

Gambar 1 menggambarkan mengenai dua komponen strategi komunikasi yang efektif yaitu strategi pesan dan strategi media dalam mencapai tujuan pemasaran menurut Machfoedz (2010).

\section{Paradigma Penelitian}

Dalam paradigma ini, peneliti menggunakan pendekatan subjektif sehingga sesuai dengan tujuan penelitian yang diharapkan peneliti. Dengan cara ini, peneliti dapat menjabarkan dan menginterpretasikan setiap makna dan realitas terkait strategi komunikasi yang dilakukan. 


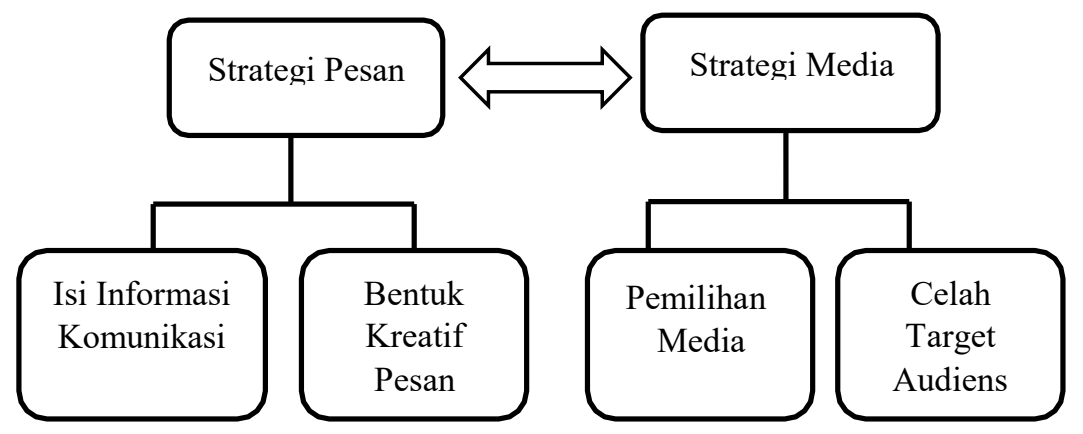

Sumber: Machfoedz (2010)

Gambar 1. Komponen Strategi Komunikasi

\section{METODE PENELITIAN}

Pada penelitian ini, peneliti menggunakan metode studi kasus. Metode studi kasus digunakan untuk menelaah sebanyak mungkin data tentang subjek dan objek yang diteliti, serta menjabarkan kasus tersebut (Pambayun, 2013). Selain itu, tipe metode kasus yang digunakan adalah tipe studi kasus tunggal yaitu sebuah metode yang menganalisis satu permasalahan suatu objek, dalam hal ini berupa strategi komunikasi komunitas virtual AboutTNG dalam mempromosikan Tangerang. Penggunaan tipe studi kasus tunggal pada penelitian ini merujuk pada ungkapan Yin (2014) bahwa kasus tunggal dapat disamakan dengan penelitian tunggal menggunakan satu objek, memiliki alasan bahwa kasus tersebut mewakili kasus yang unik, dan pada penelitian ini peneliti memiliki kesempatan untuk melakukan observasi dan analisa sebuah fenomena. Dalam hal ini, komunitas virtual AboutTNG adalah sebuah kasus yang unik karena komunitas ini digagas oleh pemuda Tangerang untuk memperkenalkan Tangerang melalui media sosial.

\section{Pengumpulan Data}

Dalam penelitian ini, penulis melakukan teknik pengumpulan data sebagai berikut:

- Data primer, dengan melakukan wawancara mendalam (in-depth interiew), observasi, dan dokumentasi.

- Data sekunder, berupa data dan informasi dari sumber-sumber seperti buku dan jurnal.

\section{Unit Analisis}

Unit analisis berupa transkrip wawancara dari informan serta teks berupa tulisan dan gambar dari akun Instagram @abouttng (Tabel 1).

Tabel 1. Kategori Analisis Untuk Panduan Penelitian

\begin{tabular}{|c|c|c|c|}
\hline Analisis & Sub Analisis & $\begin{array}{c}\text { Isi Analisis } \\
\end{array}$ & Pengumpulan Data \\
\hline $\begin{array}{l}\text { Komponen Strategi } \\
\text { Komunikasi }\end{array}$ & Strategi pesan & $\begin{array}{l}\text { 1. Isi informasi komunikasi } \\
\text { 2. Strategi kreatif pesan }\end{array}$ & $\begin{array}{l}\text { Wawancara dan observasi } \\
\text { Wawancara dan observasi }\end{array}$ \\
\hline Pemasaran yang & & 1. Pemilihan media & Wawancara \\
\hline $\begin{array}{c}\text { Efektif (Machfoedz, } \\
\text { 2010) }\end{array}$ & Strategi media & 2. Celah target audiens & Wawancara dan observasi \\
\hline $\begin{array}{l}\text { Evaluasi Strategi } \\
\text { Komunikasi }\end{array}$ & $\begin{array}{c}\text { Efek pesan yang } \\
\text { disampaikan } \\
\text { @abouttng } \\
\text { terhadap followers }\end{array}$ & $\begin{array}{l}\text { 1. Alasan followers } \\
\text { mengikuti akun Instagram } \\
\text { @abouttng } \\
\text { 2. Feedback dari followers } \\
\text { pada pesan yang diterima }\end{array}$ & Wawancara dan observasi \\
\hline
\end{tabular}

Sumber: Olahan penulis

\section{Teknik Keabsahan (Validitas) Data}

Validitas data yang digunakan adalah triangulasi sumber dengan membandingkan data hasil wawancara dengan pengamatan, membandingkan informasi yang dikatakan narasumber di depan umum dengan yang dikatakan secara pribadi, dan membandingkan 
hasil wawancara dengan isi dokumen yang berhubungan.

\section{PEMBAHASAN}

Pemaparan temuan data dan analisis data mengenai strategi komunikasi Komunitas Virtual AboutTNG dalam mempromosikan Tangerang melalui jejaring sosial Instagram.

\section{Perencanaan dan Implementasi Strategi Komunikasi Komunitas Virtual AboutTNG}

Sebelum membahas lebih dalam tentang dua komponen tersebut, peneliti akan menyajikan data tentang tahapan awal dalam pengembangan strategi komunikasi efektif, yaitu: upaya AboutTNG selaku komunikator dalam melakukan identifikasi audiens sasaran dan analisis kebutuhan khalayak.

\section{Identifikasi Target Audiens dan Analisis Kebutuhan Khalayak}

Komunitas AboutTNG sebagai komunikator dalam mempromosikan wilayah Tangerang (Kota Tangerang, Kab. Tangerang, Tangerang Selatan) melalui media sosial, dengan tagline-nya "Bangga Jadi Orang Tangerang", komunitas ini memiliki visi ingin menjadi wadah bagi anak muda Tangerang agar dekat dengan tempat tinggalnya sehingga mampu menciptakan perubahan positif bagi lingkungan sekitarnya serta mampu berkontribusi membangun wilayah Tangerang menjadi lebih maju dan berkembang.

Sejak berdiri pada tanggal 11 November 2014, AboutTNG membangun gerakan untuk mempromosikan Tangerang melalui aktivitas offline maupun online. Beberapa aktivitas offline antara lain dengan mengadakan kegiatan-kegiatan sosial, seperti GatheringTNG, JelajahTNG, GowesTNG, sedangkan aktivitas online-nya dengan memberi informasi seputar Tangerang melalui website dan sosial media seperti Twitter, Facebook, Instagram (AboutTNG, 2015). Meskipun aktivitas AboutTNG tergolong aktivitas yang secara langsung ingin mempromosikan atau memperkenalkan Tangerang ke khalayak luas, namun kelompok ini bukan didirikan oleh Pemerintah Tangerang tetapi dibentuk oleh inisiatif sekelompok anak muda.

\section{Strategi Pesan Akun Instagram@abouttng dalam Mempromosikan Tangerang Melalui Instagram}

Dalam mencapai tujuan dari aktivitas promosi,@abouttng selaku komunikator telah melakukan serangkaian tahap perencanaan hingga evaluasi komunikasi dengan strategi komunikasi yang telah ditentukan. Tujuannya adalah untuk memengaruhi anak muda Tangerang agar memiliki rasa peduli, bangga dan rasa cinta kepada Tangerang.

Setelah mengetahui secara umum alur penyusunan hingga pemublikasian konten (Gambar 2), akun Instagram @abouttng menerapkan strategi pesan berdasarkan konsep Machfoedz (2010) yang dibagi menjadi dua bagian yaitu isi informasi komunikasi dan bentuk kreatif pesan. Dalam isi informasi, akun@abouttng menyampaikan beragam informasi tentang Tangerang. Setelah menetapkan isi informasi dan repon yang ingin dicapai, proses komunikasi berlanjut ke pengembangan bentuk pesan yang kreatif.

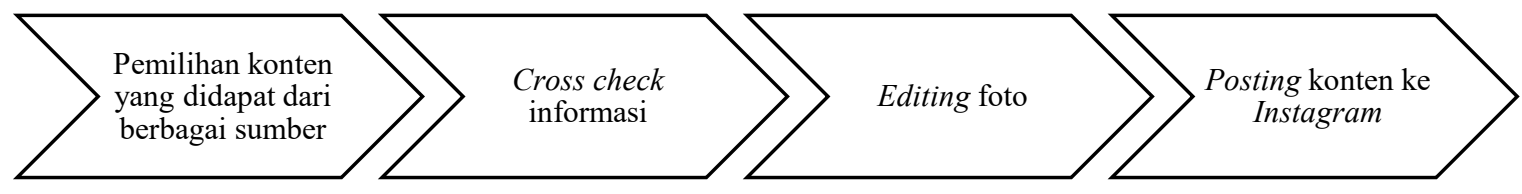

Gambar 2. Strategi Pesan Akun Instagram @abouttng 


\section{Isi Informasi Komunikasi}

Pemilihan isi informasi yang beragam pada@abouttng dilakukan agar konten tidak monoton dan semua informasi tentang Tangerang dapat tersampaikan ke khalayak (followers) sehingga tujuan yang diharapkan dapat tercapai. Dari hasil observasi, beragam isi informasi yang dipublikasikan oleh akun @abouttng, yaitu:

- Kuliner.

- Ikon-ikon kota yang ada di Tangerang.

- Destinasi wisata.

- Informasi lugas (TNGupdate).

- Informasi rutinitas di lingkungan Tangerang.

- Tempat-tempat bersejarah di Tangerang.

- Event komunitas dan event pemerintah di Tangerang.

- Konten pendukung seperti kuis.

\section{Bentuk Kreatif Pesan}

Setelah menetapkan isi informasi dan repon yang ingin dicapai, proses komunikasi berlanjut ke pengembangan pesan yang kreatif. Pengembangan pesan diperlukan agar khalayak tertarik dan terlibat dengan konten yang dipublikasikan:

1. Melakukan editing pada foto yang akan diunggah. Semua konten berupa foto atau grafis yang diunggah ke akun Instagram @abouttng selalu melalui tahap editing oleh tim desain, seperti mengatur kontras dan saturation foto, membubuhkan sumber foto, logo, website dan maskot Botang (Bocah Tangerang) sehingga tampilan kontennya akan terlihat lebih rapi dan menarik.

2. Pengembangan pesan yang efektif. Setelah menetapkan target audiens, isi informasi, dan tujuan yang diinginkan, komunikasi dilanjutkan dengan pengembangan pesan yang kreatif, yaitu:

a. Isi pesan. Setelah menetapkan tujuannya, yaitu ingin menjadi media bagi anak muda Tangerang untuk mendekatkan diri dengan tempat tinggalnya, menumbuhkan rasa cinta, peduli, dan kebanggaan, AboutTNG juga sudah menetapkan respon yang diinginkan dari audiensnya terhadap kegiatan promosi yang dilakukannya melalui Instagram, maka isi yang disampaikan berupa:
- Ide rasional atau informasional, dengan pesan yang menunjukkan kelebihan Tangerang dengan kota lain melalui foto atau penulisan caption, seperti memperlihatkan keindahan Tangerang, menginformasikan asetaset Tangerang yang belum diketahui banyak orang.

- Ide emosional, seperti rasa malu merupakan pesan yang bersifat sangat persuasif karena pesan tersebut diyakini oleh semua khalayak. Konten mengandung daya tarik emosional diyakini dapat mengajak generasi muda Tangerang untuk berkontribusi positif agar Tangerang lebih maju, bukan malah selalu menggerutu atas kekurangan Tangerang.

- Ide moral, berupa ajakan untuk berbuat baik dengan menyusun pesan mengenai sesuatu yang "benar" dan "sesuai" serta ditujukan untuk perasaan audiens, seperti ajakan menjaga lingkungan dan kerukunan beragama di Kota Tangerang menjadi contoh konten dengan menggunakan ide moral.

b. Struktur Pesan. Struktur pesan adalah cara komunikator mengendalikan, cara pengendalian pesan ini terdiri dari:

- Pengendaliannya berupa komunikator yang melakukan penarikan kesimpulan atau menyerahkannya ke audiens; penarikan kesimpulan yang paling efektif adalah penarikan kesimpulan diserahkan ke khalayak karena dapat menghasilkan respon berupa likes dan komentar.

- Pengendalian pesan dengan cara mengemukakan argumen satu sisi dengan menyebutkan keunggulan produk atau argumen dua sisi dengan menyebutkan kekurangan dan keunggulannya.

c. Format Pesan. Konten di Instagram tergolong konten bersifat visual, format pesan yang diterapkan pada konten @abouttng berupa penulisan caption yang kreatif dan tidak monoton, foto selalu dibubuhi logo, sumber foto, maskot, foto diatur saturation dan kontrasnya, dan selalu menggunakan hashtag yang sama. 


\section{Cara-Cara Penulisan Caption pada Akun @abouttng \\ Dari hasil observasi, peneliti} mengelompokkan cara-cara@abouttng menyusun pesan melalui caption agar dapat menciptakan interaktivitas dengan empat cara yaitu, penyampaian pesan dengan caption bersifat narasi, cara atraktif, formal, dan penyampaian pesan dengan kalimat editorial.

1. Naratif, karangan yang ditulis dengan teknik bercerita dengan berusaha menggambarkan sejelas-jelasnya suatu peristiwa kepada pembaca, contohnya dengan mengulas kembali cerita di lingkungan sekitar.

2. Atraktif, pesan disampaikan menggunakan simbol emoticon dan bahasa puitis, penulisan caption dengan kalimat tanya, konten dan caption dikemas dalam kuis tebak-tebakan dan kuis cari kata.

3. Formalitas atau bahasa baku, dalam pembahasan konten-konten tertentu, akun @abouttng juga menyampaikan pesan dengan penulisan dan tata bahasa baku (formalitas). Jenis-jenis konten (a)abouttng yang biasa menggunakan bahasa baku adalah konten TNGupdate dan ulasan tentang destinasi wisata.

4. Penulisan caption berupa kata sapaan dan quote, greetings yaitu kata sapaan untuk followers yang biasa digunakan saat pergantian waktu, seperti waktu pagi, waktu siang, sore, dan malam. Menurut Maryati (2016), kalimat sapaan hingga menanyakan hal yang lebih personal seperti menanyakan kabar followers ini bertujuan menjalin kedekatan dengan followers. Saat ditanya tentang penggunaan kata sapaan sebagai cara mendekatkan diri dengan followers.

\section{Pengemasan Pesan dengan Memanfaatkan Fitur-Fitur Instagram}

(a)abouttng memanfaatkan beberapa fitur-fitur Instagram untuk mengemas pesan menjadi lebih kreatif, seperti menggunakan:

1. Penggunaan hashtag khas yang sama.

2. Penggunaan hashtag khusus pada konten tertentu.

3. Pemanfaatan fitur caption.

4. Pemanfaatan fitur mention
5. Pemanfaatan fitur Instagram Stories.

6. Dihubungkan ke link-link dari website.

\section{Strategi Media Akun Instagram@abouttng dalam Mempromosikan Tangerang}

Dalam strategi media, peneliti akan membahas media yang dipilih AboutTNG dalam mempromosikan Tangerang dan celah target audiens berupa strategi waktu yang diterapkan akun@abouttng dalam mempublikasikan konten.

\section{Pemilihan Media}

Saluran komunikasi yang digunakan AboutTNG dalam mempromosikan Tangerang adalah saluran komunikasi tanpa awak atau saluran komunikasi tidak langsung. Saluran komunikasi tidak langsung yang dipilih ini berupa media sosial dan acara (event).

\section{Saluran Komunikasi Tidak Langsung (Non Personal) Berupa Jejaring Sosial Instagram} Beberapa saluran komunikasi tidak langsung berupa media sosial yang dimanfaatkan AboutTNG dalam mempromosikan Tangerang yaitu: Facebook, Instagram, personal homepages, Twitter, dan Youtube. Setiap media sosial yang digunakan komunitas AboutTNG berfungsi menyebarkan informasi yang berbeda-beda, sesuai dengan karakteristik medianya. Instagram@abouttng dimanfaatkan sebagai media untuk menyampaikan informasi yang beragam dan lebih update seperti: info lalu lintas, laporan hujan, good news seperti prestasi pelajar, bad news, informasi kuliner, tempat wisata, dan lain-lain.

Erwin (penggagas Komunitas AboutTNG) mengungkapkan bahwa sifat Instagram yang kontennya tidak tersimpan di Google Source dipilih untuk menyampaikan beragam informasi ter-update baik yang bersifat good news maupun bad news. Akun Instagram@abouttng hanya dimanfaatkan sebagai media publik yaitu media untuk menyampaikan informasi ke siapa saja bukan sebagai media komunikasi personal.

Penggunaan akun Instagram @abouttng dalam mempromosikan Tangerang dianggap paling sukses dibandingkan media sosial 
lainnya dan mampu menyampaikan pesan dengan baik karena berhasil memiliki jumlah followers paling banyak dan kenaikan jumlah followers-nya juga signifikan. Pemilihan jejaring sosial Instagram sebagai salah satu media promosi yang menyampaikan beragam informasi seputar Tangerang cukup efektif dan sesuai dengan target audiens AboutTNG yaitu kalangan muda. Dalam hal ini, AboutTNG telah menerapkan pemilihan media sesuai dengan yang dipaparkan Cangara (2014) bahwa hal yang perlu diperhatikan dalam memilih media dalah mempertimbangkan jenis media yang dipilih komunikator dengan media yang dimiliki target audiens. Kemampuan Instagram dalam menyajikan konten yang lebih visual dengan fitur-fitur menarik juga membuat Instagram menjadi salah satu media promosi yang efektif. Pemanfaatan fitur-fitur Instagram secara maksimal oleh@abouttng telah berhasil menarik perhatian pengguna Instagram.

\section{Saluran Komunikasi Tidak Langsung Berupa Event}

Beberapa saluran komunikasi berupa acara (event) yang digunakan AboutTNG untuk berinteraksi dengan khalayak yaitu: event \#GowesTNG yaitu kegiatan memperkenalkan Tangerang melalui hobi bersepeda, \#GatheringTNG yaitu acara kumpul bareng anak muda Tangerang untuk menjalin hubungan sesama warga Tangerang, berbagi ilmu, dan pengetahuan, ada acara \#JelajahTNG yaitu kegiatan yang untuk mengenal Tangerang seperti jelajah sejarah, dan lain-lain.

\section{Celah Target Audiens}

Pola update konten pada akun @abouttng dilakukan dengan menyesuaikan timeline yang telah ditentukan dan juga spontanitas. Selain itu, untuk membuat konten lebih beragam dan menjangkau target sasaran yang lebih luas, jumlah konten yang harus diunggah ke dalam akun Instagram @abouttng yaitu minimal sembilan foto dalam satu hari, tetapi jumlah ini juga disesuaikan dengan informasi yang saat itu sedang ramai dibicarakan. Hal ini disampaikan oleh founder @abouttng, bahwa:
1. Pengunggahan konten di Instagram tidak memperhatikan jam tertentu.

2. Penyampaian pesan disesuaikan dengan pergantian waktu.

3. Penyajikan konten berdasarkan momentum.

\section{Efek Pesan yang Disampaikan oleh Akun Instagram@abouttng terhadap Followers}

Efek adalah elemen terakhir dalam proses komunikasi yang merupakan pengaruh pesan atau respon komunikan setelah proses komunikasi berlangsung. Temuan dalam lingkup komunikan (followers) menjadi tiga kategori, yaitu:

1. Alasan followers mengikuti akun (a)abouttng karena akun Instagram @abouttng dianggap bermanfaat oleh followers juga banya hal menarik dalam konten@abouttng membuat followers mau menerima pesan dalam konten tersebut, yang bersifat positif dan umpan balik yang bersifat negatif.

2. Efek pesan yang disampaikan@abouttng terhadap followers.

- Efek pesan berupa umpan balik bersifat positif.

- Efek pesan berupa umpan balik yang bersifat negatif.

3. Followers mengikuti event offline yang diselenggarakan@abouttng.

\section{PENUTUP}

\section{Simpulan}

Berdasarkan hasil penelitian mengenai Strategi Komunikasi Komunitas AboutTNG dalam mempromosikan Tangerang melalui jejaring sosial Instagram, penulis dapat menarik kesimpulan di antaranya sebagai berikut:

1. Isi informasi yang disampaikan oleh akun Instagram @abouttng sangat beragam. Keberagaman isi informasi yang disampaikan@abouttng ini telah disesuaikan dengan kebutuhan target audiensnya yaitu kalangan muda yang tinggal di Tangerang.

2. Pada strategi kreatif pesan, akun @abouttng mengembangkan pesan menjadi sangat menarik, mulai dari 
melakukan editing pada foto, pengembangan pesan agar lebih efektif, penulisan caption dilakukan dengan berbagai cara, dan pengemasan pesan memanfaatkan fitur Instagram. Dengan pemanfaatan fitur Instagram, @abouttng telah menciptakan pengalaman eksklusif untuk followers-nya, contohnya penggunaan hashtag (\#) yang memudahkan pengguna men-tracking konten. Penyusunan hingga pemublikasian konten di Instagram @abouttng melalui beberapa tahapan yaitu pemilihan konten dari berbagai sumber, cross check informasi, editing foto, dan posting konten ke Instagram. Pada pengembangan pesan agar lebih efektif, @abouttng memperhatikan isi pesan, struktur pesan, dan format pesan. Bentuk kreatif pesan@abouttng selanjutnya adalah penulisan caption dengan menggunakan cara-cara kreatif.

3. Pemilihan Media. Saluran komunikasi yang digunakan AboutTNG adalah saluran komunikasi tanpa awak atau saluran komunikasi tidak langsung berupa acara (event) dan media sosial. Media sosial yang paling sukses dalam mempromosikan Tangerang adalah Instagram karena memiliki jumlah followers terbanyak dan kenaikan jumlah followers-nya juga signifikan. Sejak 6 November 2016 hingga 25 Mei 2017 pengikutnya mengalami kenaikan dari 37.300 menjadi 101.661 pengikut. Instagram dimanfaatkan AboutTNG sebagai media untuk menyampaikan informasi yang beragam dan lebih update. Pada celah target audiens, @abouttng menerapkan pola update konten dengan menyesuaikan timeline yang telah ditentukan dan juga spontanitas. Strategi waktu yang diterapkan@abouttng untuk menjangkau audiens adalah dengan menyampaikan pesan sesuai pergantian waktu (pagi, siang, sore, dan malam) dan memanfaatkan momentum seperti peringatan hari raya dan weekend.

4. Efek pesan yang disampaikan@abouttng terhadap followers merupakan efek dari proses komunikasi yang cukup berhasil karena followers bersedia untuk melakukan tindakan setelah menerima pesan dari@abouttng. Efek pesan yang disampaikan akun@abouttng kepada followers dibagi menjadi dua, yaitu efek pesan berupa umpan balik yang bersifat positif dan umpan balik yang bersifat negatif. Efek pesan yang diberikan followers berupa umpan balik bersifat positif ada yaitu: a) followers mau memberikan berbagai feedback positif pada konten berupa like, komentar, mention, repost, dan menggunakan hastag @abouttng, b) followers turut berpartisipasi pada event yang diselenggarakan @abouttng, dan c) followers mengunjungi tempat yang dipromosikan@abouttng.

\section{Saran}

\section{Saran untuk Komunitas AboutTNG}

Setelah melakukan penelitian ini, peneliti ingin memberikan saran kepada AboutTNG dalam mempromosikan Tangerang melalui jejaring sosial Instagram. Saran tersebut adalah sebagai berikut:

1. Jejaring sosial Instagram @abouttng harus lebih banyak membuat variasi konten yang kreatif agar dapat menarik khalayak lebih luas, seperti:

- Menyajikan konten video dan konten tips and trick. Penulis menyadari bahwa beberapa informasi seperti informasi wisata yang disampaikan @abouttng selalu sama yaitu dengan mem-posting foto tempat wisata tersebut. Oleh karena itu, untuk menarik perhatian followers dapat dibuat konten yang lebih bervariasi berisi tips and trick, contohnya tips and trick liburan ke alam bebas.

- Menyajikan konten yang lebih interaktif, misalnya konten yang isinya bernostalgia dengan permainan dan kebiasaan di masa kecil. Konten seperti ini diharapkan dapat menciptakan interaksi followers dan menarik perhatian untuk memberikan respon berupa komentar yang lebih banyak. Meskipun konten seperti ini tidak berhubungan dengan Tangerang, 
tetapi sangat penting untuk menarik perhatian dari followers karena jika konten tentang Tangerang tidak ditambah dengan konten yang sifatnya lebih personal dan interaktif maka khalayak akan bosan dan mulai jenuh dengan sajian konten AboutTNG. Namun, porsi konten tentang Tangerang dan konten di luar Tangerang harus tetap diperhatikan agar tujuan yang diinginkan tetap tercapai.

2. Dalam pelaksanaan event offline seperti JelajahTNG, GatheringTNG, Goes to School, diharapkan@abouttng banyak melibatkan followers untuk menjadi panitia kegiatan tidak hanya dari anggota internal komunitas, seperti ada perekrutan panitia yang disebarkan melalui jejaring sosial. Melalui cara ini, keterlibatan followers pada kegiatan mengenal Tangerang dan kontribusi anak muda terhadap Tangerang akan semakin banyak.

\section{Saran Untuk Penelitian Selanjutnya}

Saran untuk penelitian selanjutnya yang melakukan analisis mengenai strategi komunikasi pemanfaatan jejaring sosial dalam aktivitas promosi diharapkan dapat mengembangkan penelitian menjadi lebih dalam mengetahui efek pesan yang disampaikan komunikator terhadap followers dengan menyajikan data kuantitatif. Tujuannya adalah untuk mengukur efektivitas aktivitas promosi yang dilakukan sebuah kelompok melalui jejaring sosial dengan mengetahui efek pesan yang disampaikan komunikator kepada komunikan.

\section{DAFTAR PUSTAKA}

AboutTNG (2015) Tentang Kami - About Tangerang. [Online]. 2015. Available from: http://abouttng.com/tentang-kami/ [Accessed: 9 October 2016].

Ahmad, T.Y., Nursih, I. \& Praceka, P.A. (2014) Pemanfaatan jejaring Sosial Soundcloud Sebagai Media promosi Band Indies Myviolaine Morning. [Online]. Universitas Sultan Ageng Tirtayasa. Available from: http://repository.fisip-untirta.ac.id/387/

[Accessed: 9 October 2016].
Akbar, R.F. (2016) Strategi Komunikasi Media Sosial Dalam Program One Day One Juz. [Online]. UIN Syarif Hidayatullah. Available from:

http://repository.uinjkt.ac.id/dspace/handle/1 $23456789 / 32342$.

APJII (2016) Penetrasi dan Perilaku Pengguna Internet Indonesia 2016. [Online]. Available from:

https://apjii.or.id/downfile/file/surveipenetra siinternet2016.pdf.

Apriliani, N.N., Putri, Y.R. \& Ali, D.S.F. (2015) Pengaruh Penggunaan Media Twitter @infobdg Terhadap Pengurangan Ketidakpastian Informasi (Survey pada Mahasiswa Angkatan 2014 Universitas Telkom). Jurnal Sosioteknologi. [Online] 14 (2), 160-169. Available from: doi:10.5614/sostek.itbj.2015.14.2.6.

Cangara, H. (2014) Perencanaan dan Strategi Komunikasi. Jakarta, Raja Grafindo Persada.

Gupta, S. \& Kim, H.-W. (2004) Virtual Community: Concepts, Implications, and Future Research Directions. In: Proceedings of the Tenth Americas Conference on Information Systems. [Online]. 2004 New York. pp. 2679-2687. Available from: http://www.virtual-

communities.net/mediawiki/images/4/4a/SI

GEBZ05-1115.pdf [Accessed: 23 May 2017].

Hestya, R.P. (2013) Instagram 'Penguasa Bisnis' di Media Sosial. [Online]. 2013. Tempo.co. Available from: https://tekno.tempo.co/read/536145/instagra m-penguasa-bisnis-di-media-sosial

[Accessed: 9 October 2016].

Jones, A.T., Malczyk, A. \& Beneke, J. (2011) Internet Marketing: A Highly Marketing Guide to Every Aspect of Internet Marketing. [Online]. GetSmarter Internet Marketing Textbook. Available from: https://open.uct.ac.za/handle/11427/4154.

Machfoedz, M. (2010) Komunikasi Pemasaran Modern. 1st edition. Yogyakarta, Cakra Ilmu.

Maryati, L. (2016) Strategi Komunikasi Penggunaan Twitter dalam Kegiatan Promosi Kuliner (Studi Kasus Strategi Komunikasi Penggunaan Media Sosial TwitterolehAkun@TongkronganSolodalam Kegiatan Promosi Kuliner di Kota Solo). [Online]. UNS (Sebelas Maret University). Available from: https://digilib.uns.ac.id/dokumen/detail/5143 7/Strategi-Komunikasi-Penggunaan-Twitterdalam-Kegiatan-Promosi-Kuliner-StudiKasus-Strategi-Komunikasi-Penggunaan- 
Media-Sosial-Twitter-oleh-Akun-

TongkronganSolo-dalam-Kegiatan-Promosi-

Kuliner-di-Kota-Solo [Accessed: 12

February 2017].

Morissan, M.A. (2010) Periklanan: Komunikasi Pemasaran Terpadu. Jakarta, Kencana Prenada Media Group.

Nasrullah, R. (2015) Media Sosial: Perspektif Komunikasi, Budaya, dan Sosioteknologi. 1st edition. Bandung, Simbiosa Rekatama Media.

Nasrullah, R. (2014) Teori dan Riset Media Siber (Cybermedia). 1st edition. Jakarta, Kencana Prenada Media Group.

Pambayun, E.L. (2013) One Stop: Qualitative Research Methodology in Communication: Konsep, Panduan, dan Aplikasi. TB. Massa Djafar (ed.). Jakarta, Lentera Ilmu Cendekia. Rheingold, H. (1993) The Virtual Community: Homesteading on the Electronic Frontier. [Online]. Available from: http://www.rheingold.com/ve/book/intro.ht $\mathrm{ml}$.

Septiawan, A.R. (2015) Strategi Komunikasi Pemasaran Buku Dalam Meningkatkan Penjualan Melalui Media Sosial Instagram (Studi Deskriptif Pada Founder@ Tausiyahku_. UIN Sunan Kalijaga.

Utami, M.A., Lestari, M.T. \& Putri, B.P.S. (2016) Strategi Komunikasi Pemasaran SMB Telkom University Tahun2015/2016 Melalui Media Sosial Instagram. Jurnal Sosioteknologi. [Online] 15 (2), 309-318. Available from: http://journals.itb.ac.id/index.php/sostek/arti cle/view/2091/1533.

Yin, R.K. (2014) Studi Kasus: Desain dan Metode. 1st edition. Jakarta, Rajawali Pers. 